\title{
Los salarios dentro del sistema del repartimiento forzoso en el Valle de México, 1549-1632
}

\section{Sander Spanoghe}

Universidad Estatal de Gante, Bélgica

Este artículo contiene un análisis del salario dentro del repartimiento forzoso, principal sistema de reclutamiento de mano de obra indígena en el Valle de México desde aproximadamente 1550 hasta 1632.

Primeramente establezco el valor nominal de los salarios, basándome en fuentes secundarias. En segundo lugar diferencio los salarios según los sectores económicos, consultando fuentes primarias. Después calculo el valor real de estos salarios a base de los precios de maíz y del mínimo socio-vital. Una comparación de los salarios pagados dentro con los dados fuera del repartimiento constituye un tercer método para valorar dichos salarios, mientras el cuarto consiste en una investigación de la relación entre tributo y salario. Siguen las conclusiones, que consideran el salario dentro de su contexto histórico y geográfico, concluyendo que este salario no fue una realidad "real" sino una realidad legal, instituido para callar la conciencia y la crítica de la política laboral colonial.

\section{Fuentes y Metodología}

Este estudio sobre los salarios dentro del repartimiento forzoso representa un intento de análisis de un aspecto del sistema que, aun siendo quizás el más particular, es sin duda el más importante, a saber, el fenómeno de los salarios tasados. ${ }^{1}$ Consideramos el aspecto del salario el más particular porque introdujo por primera vez de forma generalizada un elemento de la economía capitalista mercantil europea en una estructura laboral casi feudal. El repartimiento constituyó la primera etapa en un intento organizado de incorporar a los vasallos indígenas a una estructura económica

* Este artículo ha sido elaborado bajo la dirección de la Dra. Manuela Cristina García Bernal, de la Universidad de Sevilla.

1 Seguimos en este artículo la definición del repartimiento forzoso (que a continuación simplemente designamos por repartimiento) como la desarrolló Charles Gibson, a saber: "la institución que dominó el reclutamiento de trabajadores indígenas por un período de cerca de 75 años después de mediados del siglo [XVI]. Fue un sistema de trabajo racionado, rotativo, y supuestamente de interés público o para utilidad pública, que afectaba tanto a los indígenas de encomienda como a los que no entraban dentro de la encomienda, y que beneficiaba a una clase de patronos mucho más amplia de lo que había sido posible bajo la encomienda." También hemos utilizado el análisis de la evolución histórica del repartimiento forzoso como está señalado en la misma obra. Gibson, Ch.: Los aztecas bajo el dominio español, México, 1967, pág. 229 (definición) y págs. 229-247 (evolución histórica). 
capitalista como verdaderos participantes, al vender, aunque fuera forzadamente, su trabajo en el mercado laboral colonial. Así, la Corona española quiso acabar con la situación que se había observado en el período de la encomienda antes de la ley de 1549, es decir, el indio valorado como mero factor de producción gratuita. ${ }^{2}$

Al mismo tiempo el aspecto del salario es considerado como el más importante, porque representó la base de justificación de todo el sistema, visto el hecho de que los españoles ya consideraban el trabajo prestado por terceros como libre desde el momento en que el amo tenía que pagar sueldos, aunque normalmente esta misma labor supusiera un alto grado de compulsión. ${ }^{3}$ De este modo se pudieron resolver dos problemas a la vez. Por una parte, se consiguió acallar tanto la conciencia real como la de los religiosos escrupulosos, siempre torturados por la cuestión del buen tratamiento de los vasallos indígenas. Por otra, se logró que el abastecimiento de mano de obra beneficiase a una amplia clase de amos españoles con una remuneración mínima, pudiéndose compensar la poca fuerza de atracción de los bajísimos salarios con un alto grado de compulsión, justificado por el hecho de que los trabajos realizados bajo este sistema cumplían con el propósito del bien común, y por la idea que se solía tener sobre los indígenas: unos vagos flojos, siempre inclinados a la ociosidad. ${ }^{4}$

A pesar de la importancia del tema, solamente hemos podido encontrar datos bastante precarios que hacen que los resultados tampoco lleguen a ser verdaderamente convincentes. Sin embargo, creemos que los obtenidos, aunque sean precarios, pueden dar pistas para una reflexión más completa, apoyada por investigaciones de fuentes primarias. De todas maneras, consideramos conveniente justificar nuestro procedimiento y los esquemas que hemos utilizado para interpretar los datos históricos.

$2 \mathrm{El}$ aspecto de la introducción del indio en el sistema económico occidental está analizado por Florescano, E.: "La formación de los trabajadores en la época colonial, 1521-1770" en Florescano, E. (ed.): La clase obrera en la historia de México, de la colonia al imperio, México, 1980, Vol. I, págs. 9-125. A continuación se podrá notar que nosotros no estamos de acuerdo con su punto de vista. Para la interpretación del contenido de la ley de 1549 (Recopilación de las Leyes de los Reynos de las Indias, Lb. VI, Tit. XII, ley 1) véase Zavala, S.: El servicio personal de los Indios de la Nueva España, México, 1987, Vol. I, págs. 40-42.

3 Borah, W. y S.F. Cook: Price Trends of some Basic Commodities in Central Mexico, 1531 1570, Berkeley, 1958, pág. 39.

4 Para esta imagen del indio véase la Recopilación de las Leyes de los Reynos de las Indias, Lb. VI, Tit. XII, ley 1, y el análisis de la consulta sobre los repartimientos de los indios que se hizo en el Tercer Concilio Provincial Mexicano (1585) en Llaguno, J.A.: La personalidad jurídica del indio y el Tercer Concilio Provincial Mexicano, México, 1963, págs. 87-114 y págs. 235-270. 
Primeramente, trataremos de establecer los valores nominales de los salarios pagados dentro del repartimiento forzoso durante el período 15501633. Como fuentes básicas hemos utilizado la parte importante que sobre el trabajo contiene el libro de Gibson, combinada con el análisis ofrecido por Borah y Cook, pues, aunque estos últimos sólamente analizan el período 1530-1570 - con extrapolaciones muy útiles hasta 1590 - ya hacen un primer esfuerzo de relacionar los salarios nominales con su valor real, al calcular la cantidad de oro que se podía comprar con los mismos. ${ }^{5}$ Después intentaremos confirmar estos resultados mediante la comparación con fuentes primarias publicadas en los cuatro primeros volúmenes de la Colección de las Fuentes para la Historia del Trabajo en Nueva España. ${ }^{6}$

Una segunda parte del análisis del aspecto de los salarios dentro del repartimiento consistirá en un intento de calcular los salarios reales y de relativizar su significado histórico. Es lógico pensar que para realizar semejante cálculo necesitamos trabajar con precios de productos básicos. Pero como los datos ya publicados y analizados de estos precios del siglo XVI en la Nueva España escasean de una manera alarmante, los resultados obtenidos van a ser precarios. No obstante, contamos con el primer esfuerzo y ejemplo de Borah y Cook para el período 1530-1590 ya mencionado. Partiendo de sus resultados como base y anunciando el carácter hipotético de nuestro análisis en cuanto al período 1590-1633, estamos convencidos de que el trabajo en sí ya constituye un ejercicio bastante útil para acercarnos al valor real del salario dentro del repartimiento.

\section{Los salarios nominales y su evolución}

Los primeros servicios de los indios a los españoles fueron en la mayoría de los casos gratuitos y se asignaron a los encomenderos por vía de tributo a cambio de la protección y de la doctrina que los beneficiarios debían impartir a los indios. ${ }^{7}$ Hacia 1549, fecha de gran transcendencia para la historia del trabajo en Nueva España, el salario normal por un día

5 Gibson: Los aztecas..., págs. 225-262. Borah y Cook: Price Trends..., págs. 13-19 (precios del maíz), 38-46 (precios del trabajo) y 46-49 (salarios reales).

6 Zavala, S. y M. Castelo: Fuentes para la historia del trabajo en Nueva España, México, 1939-1946, 8 Vol. (abreviado como FHT).

7 Zavala: El servicio personal..., Vol. I, pág. 19. 
de alquiler en trabajo no cualificado era de un cuartillo $(8,5$ maravedís $){ }^{8}$ Pero este salario fue rechazado por ser una remuneración inadecuada, y bajo el gobierno de don Luis de Velasco, hacia 1550, los salarios se fijaron en 12 mrs. (mencionamos los salarios diarios) para los trabajadores no cualificados (peones) y $24 \mathrm{mrs}$. para los trabajadores cualificados (oficiales). Los salarios aumentaron a $17 \mathrm{mrs}$. para los peones y a $34 \mathrm{mrs}$. (un real) para los oficiales en 1553, aunque también hubo salarios de 13,5 mrs. a los peones y $28,5 \mathrm{mrs}$. a los oficiales en esta misma época. ${ }^{9} \mathrm{El}$ salario de los peones aumentó a $22,5 \mathrm{mrs}$. en 1560 y a $25,5 \mathrm{mrs}$. en 1570 . No obstante, el salario de 22,5 mrs. para los peones sobrevivió en algunas zonas hasta alrededor de $1590 .{ }^{10}$ En este último año el salario de los peones aumentó a 34 mrs. y a 68 mrs. para los oficiales. ${ }^{11}$ Los salarios de los peones aumentaron a $51 \mathrm{mrs}$. en el período de $1603-1610$ y a $68 \mathrm{mrs}$. en $1629 .{ }^{12}$

Concluimos que durante el período de 1550-1570 los salarios nominales aumentaron muy rápidamente, mientras que durante la época 15701590 se puede observar un descenso en la tasa de aumento, para después volver a acusar un notable crecimiento en el período $1590-1633 .{ }^{13}$

Además, a estas escalas de salarios se añadían, en ciertas circunstancias, los alimentos diarios y una paga extra por la ida y vuelta al trabajo. En el repartimiento, cinco o seis leguas de marcha eran consideradas como el equivalente de un día de trabajo y en consecuencia, eran pagadas, aunque con una variedad de excepciones. Posteriormente, el suministro de comida

8 Gibson: Los aztecas..., pág. 254. No obstante, para el período 1524-1544, Borah y Cook (Price Trends..., pág. 44) dan un aumento en los salarios nominales de una media de 0, 67 granos de oro (=+/- $15 \mathrm{mrs}$.) a quizás una media de 1,4 granos de oro (=+/- $32 \mathrm{mrs}$.) al día. Probablemente esto sea debido a la mala situación documental que se suele encontrar para esa época, puesto que ambos solamente toman en consideración el trabajo no cualificado. Pero como las fechas de la discrepancia son muy anteriores a las fechas de la época a la que este estudio está dedicado, la contradicción no va a influir en nuestras conclusiones. En cuanto a la fecha de 1549, la ley que se promulgó en ese año constituyó el primer esfuerzo efectivo de la Corona para sustituir el trabajo no recompensado por un sistema rotativo de alquiler (véase Gibson: Los aztecas..., pág. 228 y nota 3 de este artículo).

9 Gibson: Los aztecas..., pág. 254 (señala por error el año de 1560).

10 Ibídem, págs. 254-255 y nota 160.

11 Ibídem, págs. 254-255 y nota 161.

12 Ibídem, pág. 255. De esta evolución teórica del salario nominal dentro del repartimiento no se puede deducir que las órdenes virreinales tuvieran el poder de establecer salarios iguales en todos los sectores de la economía novohispana. Aun más, se observa que fue en el sector de las obras públicas donde se daban las mayores irregularidades (cfr. apartado 3).

13 El análisis del aumento de los salarios nominales para el período 1544-1610 también es ofrecido por Borah y Cook: Price Trends..., págs. 44-45, si bien ellos solamente tienen en cuenta la evolución de los salarios de los peones, puesto que esta clase formaba la vasta mayoría de la reserva laboral constituida por los indios. Con todo, confirma las ya citadas cifras de Gibson, así que podemos utilizar ambos estudios como complementarios. 
para los trabajadores coaccionados se hizo común en los repartimientos. En el primer período, sin embargo, los indios suministraban sus propios alimentos, hecho que generó situaciones lamentables de malnutrición de estos trabajadores puesto que su comida tradicional se pudría rápidamente. ${ }^{14} \mathrm{El}$ costo del alquiler de sustitutos en el trabajo del repartimiento (pago que efectuó el trabajador a fin de evitar su obligación laboral semanal) equivalía al doble de la paga del repartimiento, subiendo de 8 reales a la semana en 1570 a 10 ó incluso 12 reales en $1590 .{ }^{15}$ También falta decir que en el servicio obligatorio a los gobernadores y caciques los peones del siglo XVI recibían sumas mucho más modestas, generalmente de 20 a 25 cacaos, más su alimento diario.

\section{CUAdRo I}

\section{SALARIOS NOMINALES Y SUS ALZAS RELATIVAS}

\begin{tabular}{cclcc} 
& & & \multicolumn{2}{c}{ Alzas relativas } \\
Período & peones & oficiales & peones & oficiales \\
\hline $1530-1549$ & $81 / 2 \mathrm{mrs}$. & $17 \mathrm{mrs}$. & - & - \\
$1550-1552$ & $12 \mathrm{mrs}$. & $24 \mathrm{mrs}$. & $+30 \%$ & $+30 \%$ \\
$1553-1559$ & $17 \mathrm{mrs}$. & $34 \mathrm{mrs}$. & $+30 \%$ & $+30 \%$ \\
& $13,5 \mathrm{mrs}$. & $28,5 \mathrm{mrs}$. & $+12,5 \%$ & $+19 \%$ \\
$1560-1569$ & $22,5 \mathrm{mrs}$. & $34 \mathrm{mrs}$. & $+25 \%$ & $+0 \%$ \\
$1570-1589$ & $25,5 \mathrm{mrs}$. & $34 \mathrm{mrs}$. & $+12 \%$ & $+0 \%$ \\
$1590-1628$ & $22,5 \mathrm{mrs}$. & & $+0 \%$ & \\
$1603-1628$ & $34 \mathrm{mrs}$. & $68 \mathrm{mrs}$. & $+25 \%$ & $+100 \%$ \\
$1629-1633$ & $51 \mathrm{mrs}$. & $68 \mathrm{mrs}$. & $+33 \%$ & $+0 \%$ \\
& $68 \mathrm{mrs}$. & $?$ & $+25 \%$ & $+?$ \\
& & & &
\end{tabular}

\section{Las diferencias de salarios, según los sectores económicos}

En cuanto al trabajo forzoso asalariado en la agricultura se nota inmediatamente la diferencia de salario entre los peones que fueron pagados por amos españoles y los que fueron remunerados por amos indios, pues-

14 Gibson: Los aztecas..., págs. 257-258.

15 Ibídem, págs. 255-256. 
to que los primeros debían pagar en moneda acuñada, mientras que los últimos pagaban "lo que es uso y costumbre entre ellos": en granos de cacao. ${ }^{16}$ Ahora bien, esta forma de pagar en unidades de cuenta solamente fue aceptada por los indios dentro de un contexto tradicional de servicios prestados a sus caciques o a otros principales, mientras que fue rechazada cuando los españoles quisieron remunerar a sus labradores en cacao. Lo prueba un documento en el que se observa cómo los indios, que se quejaron de ser pagados en cacaos, obtuvieron un mandamiento virreinal que obligó al amo español a pagar a sus peones en dinero: "de suerte que queden satisfechos". ${ }^{17}$ Igualmente extraño es que los caciques tuvieran que recurrir al repartimiento para poder disponer de los indios de sus comunidades para el trabajo en sus campos, aunque quizá ello refleja la debilitación del poder del cacique. Si aceptamos una equivalencia de +/- 100 granos de cacao por real a mediados del siglo XVI y si suponemos que esta equivalencia se mantuvo durante todo el período estudiado (1550-1633), tenemos que concluir que el salario del indio repartido en actividades en favor de la nobleza indígena estaba bastante mal remunerado, puesto que no constituyó más que el equivalente de un cuartillo y la comida. ${ }^{18}$ Consecuentemente, el mismo indio repartido podía ganar desde 5,5 hasta 8 mrs. más al día en actividades económicas en favor de los españoles. En lo que toca a los salarios pagados por los agricultores españoles, se ve que los mandamientos virreinales exigían el pago del salario anteriormente fijado por instrucción virreinal. ${ }^{19}$

Respecto a la práctica del salario en la actividad minera se nota que muchas veces una parte del mismo consistía en el suministro de alimentos a los indios mineros coaccionados. Así, se observa que en los años de 15751590 ese salario, tasado por el virrey en 22,5 maravedís, era pagado en un $25 \%$ en comida. Este era un procedimiento legal, puesto que los mineros

16 Salarios en cacaos en contextos tradicionales son mencionados en los siguientes mandamientos virreinales (si no está señalado expresamente de otra manera, los documentos que vamos a utilizar son todos mandamientos virreinales): FHT, Vol. I, docs. CII (25 cacaos + comida diaria, 1576), CVIII (20 cacaos + comida diaria, 1576), CXLV (25 cacaos + comida diaria, 1576); Vol. II, docs. LVI (25 cacaos + comida diaria, 1576), LVII (25 cacaos + comida diaria, 1576), CLII (25 cacaos + comida diaria, 1580).

17 FHT, Vol. II, doc. CLXXVI.

18 Equivalencia señalada en Borah y Cook: Price trends..., págs. 36-37.

19 FHT, Vol. I, doc. CXIV (medio real + comida diaria, 1576); Vol. II, doc. CCXXXIII (4 reales por semana, 1580); Vol. III, docs. XCIX (6 reales, 1590), CIV (6 reales, 1590), CLXXIII (6 reales por seis días de trabajo, 1591), CLXXVIII (6 reales, 1591), CXCIV (6 reales, 1591), CCV (6 reales, 1591), CCVIII (6 reales, 1591), CCXII (6 reales, 1591); Vol. V, doc. LXXXIII (un real y de comer al día, 1603). 
fueron obligados a pagar estos salarios por mandamiento virreinal. Probablemente, tal reglamentación fuese debida a las grandes distancias que separaban los pueblos suministradores de mano de obra de las minas, lo que hizo que las mujeres indias no pudieran llevar comida a sus esposos. Pero solamente si aceptamos que la comida de verdad costaba el $25 \%$ de un salario de 22,5 maravedís al día, podemos concluir que en realidad los pagos fuesen ejecutados como lo exigían y tasaban los virreyes respectivos. ${ }^{20}$ Muy notable también es el hecho de que sólo desde 1600 se empezó a exigir en los mismos mandamientos que el pago de la ida y vuelta al trabajo fuese ejecutado, lo que probablemente alude a la negligencia o al oportunismo que los mineros solían demostrar. Nótese que este pago pudo diferenciarse según la situación del camino a seguir. ${ }^{21}$

En cuanto a los salarios establecidos por orden virreinal en el sector de la industria, se nota que los pagos hasta comienzos de la última década del siglo XVI solían ser más bajos que los exigidos en los otros sectores (menos el de las obras públicas). Ello quizá se explica por el deseo de estimular la industria indiana y su desarrollo, política real que se dio hasta la década mencionada y que desapareció después ante el objetivo de proteger a la industria peninsular, amenazada en su mercado monopolizado de las Indias por los productos indianos. Se observa así que posteriormente fueron exigidos en este sector los mismos salarios que en los otros sectores económicos. ${ }^{22}$

En los salarios dispuestos para los servicios domésticos satisfechos por indígenas reclutados por vía de repartimiento se nota la misma distinción, que se apreció en el sector de la agricultura, entre pagos realizados por indios (en cacaos) y por españoles (en reales). También se observa

20 FHT, Vol. I, docs. CLII (medio real al día + comida, 1576), XXXIII (medio real al día + comida, 1576); Vol. III, docs. LXXII (medio real al día + comida, 1587), CXX (6 reales por semana de seis días, 1590), CXLI (6 reales, 1591), CLXIII ("forma que está dada", 1591); Vol. IV, doc. CLXXXII (caso de malpago en ropa, 1600); Vol. VI, docs. CCLV (instrucción a un juez repartidor para la minería, 6 reales y no en otra cosa, 1607), CD (paga en sombreros viejos, cuchillos, jabón... tiene que ser sustituido por lo estipulado = real y medio al día, 1629).

21 FHT, Vol. IV, docs. CCXI (6 reales por seis días + ida y vuelta, 1600), CCXII (6 reales por semana + ida y vuelta, 1600); Vol. VI, docs. LII (1 real por cada cinco leguas, 1606), CXXXI (1 real por cada 6 leguas, 1607), CCXV (15 reales por quince días + ida y vuelta a 1 real por seis leguas + comida diaria a $1 / 2$ tomin al día, 1607).

22 FHT, Vol. I, docs. LXXXVI (medio real al día y comida, 1576), XC (medio real al día, 1576); Vol. II, doc. CCXL (medio real al día, 1580); Vol. III, docs. III (el jornal acostumbrado, 1587), L (4 reales por una semana de ocho días, 1587), LXXVIII (4 reales por seis días + ida y vuelta, 1587), CLXXXVI (6 reales por semana, 1591); Vol. V, doc. V (9 reales por semana, 1602); Vol. VI, doc. CCCLXI (caso de malpago, 3 tomines por ocho días en vez de los debidos 9 reales). 
aquí que los caciques, principales y gobernadores indios tuvieron que recurrir al repartimiento para poder asegurarse los servidores que les exigía su status social, pero que parece ser les negaban sus propios indios subordinados. ${ }^{23}$ Por otra parte, es evidente que a los españoles se les exigieron los pagos tasados por orden virreinal, aunque hay un caso en que se autorizó moderar el salario "atento a la pobreza en que los dichos vecinos habían quedado". ${ }^{24}$

En lo que concierne a los salarios pagados por prestaciones laborales en las obras públicas se observan las malas remuneraciones que los indios solían tener en este sector, por lo menos hasta principios del siglo XVII, recurriéndose a términos bastante vagos para designar el salario a pagar en muchos casos. Todo esto nos parece relacionado y justificado por el aspecto de utilidad pública que tuvieran estas actividades, aunque en realidad esta utilidad se interpretó unilateralmente hacia la parte española de la población. Al mismo tiempo se dejaban las obras públicas para los indios, o por lo menos su organización, en manos del Cabildo de la comunidad indígena, la cual recurría al coatequytl para reclutar mano de obra no remunerada dentro de la propia comunidad. ${ }^{25}$

Finalmente, los trabajos en las obras eclesiásticas hasta muy tarde sólo se solían pagar si la obra se realizaba (parcialmente) en beneficio de la república española, aunque en estos casos eran remunerados como cual-

23 FHT, Vol. I, doc. XXVI (25 cacaos + comida diaria, 1575); Vol. II, docs. XVIII (25 cacaos + comida diaria, 1579), XXVI (25 cacaos + comida diaria, 1579), XXIX (25 cacaos + comida diaria, 1579), XXXIV (25 cacaos + comida diaria, 1579), XLIII (25 cacaos + comida diaria, 1579), LIII (25 cacaos + comida diaria, 1579), LXXXIII (25 cacaos + comida diaria, 1580), CVIII (25 cacaos + comida diaria, 1580), CXVIII (25 cacaos + comida diaria, 1580), CLXIII (25 cacaos + comida diaria, 1580), CLXV (25 cacaos + comida diaria, 1580), CLXXIII (25 cacaos + comida diaria, 1580), CLXXIV (25 cacaos + comida diaria, 1580), CXLIII (25 cacaos + comida diaria, 1580), CCLX (25 cacaos + comida diaria, 1580), CCLXV (25 cacaos + comida diaria, 1581), CCLXXV (25 cacaos + comida diaria, 1580).

24 FHT, Vol. III, docs. CIII (6 reales por seis días de trabajo, 1590), CLXXXIV (6 reales por seis días + albañil doblado, 1591), CCII (6 reales, 1591), CCXV (6 reales, 1591); Vol. IV, docs. LXXIII ("atento a la pobreza en que los dichos vecinos habían quedado se moderase el salario", 1599), XCI (un real al día + bastimentos, 1599); Vol. VI, doc. CDXC (el juez repartidor solamente paga 2 reales a los indios que asignó a su propia persona en vez de los 9 reales estipulados, 1631).

25 FHT, Vol. I, docs. CLIII ("a su contento", 1576), CLIV ("lo que es uso y costumbre”, 1576), LXXXIX (un cuartillo al día + comida, 1576); Vol. II, docs. CXX ("a su contento", 1580), CLXXIX ("pagándoles su trabajo", 1580), CXXXII (25 cacaos + comida diaria, prestaciones laborales de los sujetos en la cabecera por la propia comunidad, 1580), CLXXXIII (3 reales por semana + comida diaria, 1580); Vol. III, doc. CLXIV (6 reales por seis días de trabajo, reparo de un molino probablemente con amo privado, 1590); Vol. IV., doc. CC (6 medios reales para cada indio, 1600); Vol. V, doc. XV (1 real al día + comida diaria, 1602); Vol. VI, docs. CXVIII (9 reales por semana, 1606), CLXVIII (1 real y medio al día, 1607). Para el coatequytl véase Gibson: Los aztecas..., págs. 227 y 230-231. 
quier otra actividad económica que se aprovechase de la mano de obra indígena reclutada por vía del repartimiento. Dentro de las comunidades puramente indígenas, los frailes, continuaban, sin embargo, pidiendo mano de obra más o menos voluntaria en los pueblos en que trabajaban. No obstante, después del Tercer Concilio Provincial Mexicano los religiosos se pusieron de acuerdo en pagar a sus indios trabajadores los salarios que les exigían las leyes virreinales. ${ }^{26}$

\section{La realidad del salario}

Otro aspecto no menos importante del análisis de los salarios nominales es el de si estos pagos se efectuaban realmente o no, y, si en verdad se pagaban, a quiénes se hacía. En cuanto a la primera duda, se encuentran muchos documentos en las fuentes referentes a mandamientos virreinales que fueron inspirados por quejas de los indios de ser mal pagados. Además la duda sobre si los indios fueron agraviados muchas veces por sus amos españoles dentro del repartimiento se convierte en certeza cuando se nota que el virrey, en cada mandamiento de asignación especial de indios de servicio, siempre mencionaba los salarios a pagar por los españoles beneficiados. Pero la prueba más convincente de que ese pago dentro del repartimiento era más bien una cosa aleatoria que regular la constituye la "Nueva orden sobre la paga y tratamiento de los indios de los repartimientos de esta Nueva España (...) y mala paga que les hacen", decretada en México el día 25 de agosto del año 1599, que citamos aquí parcialmente:

"Primeramente que el día del repartimiento y al mismo tiempo de darle a cada uno
los indios que ha de llevar, se haga cuenta del salario y jornal que al cabo de la sema-
na o mes porque se reparten los indios han de haber y esto deposite luego la persona
que los llevare y se ponga en una arquilla de tres llaves que la una tenga el juez repar-
tidor y las otras dos los diputados que fueren por su turno como es costumbre y a los
indios se les de a entender que allí queda depositado el dinero de su jornal para que a
cabo de su tequio no tengan que aguardar al minero, labrador o otra persona que les
ha de pagar sino que se vengan a la misma parte donde fueron repartidos que allí se
lo darán". ${ }^{27}$

26 FHT, Vol. II, doc. CLXXXII ("conforme a lo que los labradores les paguen”, 1580); Vol. III, doc. C (6 reales por semana, 1590); Vol. IV, doc. CLXXIV ("jornales que ellos suelen ganar", 1600); Vol. VI, docs. CCXCIII (malpagado $=6$ tomines por quince hasta veinte días, 1617), CDXXVI ( 2 reales al día, 1629).

27 FHT, Vol. IV, doc. LXXIX (págs. 317-321). 
Este documento no puede entenderse de otra manera que como el último medio del virrey para garantizar el pago a los indios del repartimiento, pago que hasta que salió esta orden, y probablemente también después, fue mal efectuado. Ya queda claro que tal hecho sólo puede ser explicado por la contradicción interna del repartimiento, pues propuso salarios como método de atraer la fuerza laboral de los indios, mientras que al mismo tiempo garantizó esta atracción por vía de la coacción. Los amos españoles no hicieron más que reducir el repartimiento a su elemento coactivo, sabiendo que, si no eran denunciados por sus trabajadores, el suministro de mano de obra estaba garantizado por el Estado, aun sin pagar o pagando mal.

En cuanto a la segunda duda, sobre a quiénes fueron pagados los salarios, podemos suponer que muchas veces no fue el indio trabajador el beneficiado, basándonos en los avisos que el agustino fray Alonso de Veracruz dio en 1566 al nombrado virrey de México, marqués de Falces, en los que exponía entre otras cosas:

\footnotetext{
"Es de mucho advertir que así como solían ir indios de los pueblos por tributo a las minas, ahora van alquilados y este alquiler, porque su manera de gobierno es así, no se hace con los que lo han de trabajar sino con el cacique o gobernador o principal, y éste toma la paga de todo y éste les manda ir". ${ }^{28}$
}

\section{Los salarios reales}

El fin de este análisis es establecer el valor real de los salarios obtenidos por los indígenas a través del trabajo dentro del repartimiento. Es decir, se trata de convertir el valor monetario relativo en un valor real a través de un procedimiento de comparación con el precio de un producto determinado. Dicho de otro modo, valoramos la capacidad adquisitiva indígena en un mercado europeizado en el que el dinero era el único medio de cambio. Con todo, somos conscientes del hecho de que esta situación de mercado solamente se dio para un muy limitado grupo de indígenas artesanos en la ciudad. También reconocemos las muchas dificultades metodológicas que presenta tal procedimiento, a pesar de ser el único para valorar una remuneración eventual del indígena por parte de sus amos españoles de una

28 Avisos publicados en Zavala: El servicio personal..., Vol. II, págs. 99-102. 
manera más completa y objetiva. Por ello vamos a criticar nuestros propios métodos y resultados a través del análisis.

El mejor método para valorar la capacidad de compra de los mencionados salarios es por vía de comparación del número de reales que el indio recibía al día con la cantidad de maíz que podía comprar con esos reales. Después de todo, el maíz era el producto más importante dentro del consumo total de los indios. ${ }^{29}$

\section{El valor en maíz de los salarios}

Empezemos con unas observaciones sobre los precios del maíz. En general hubo un alza en el precio de este producto que empezó alrededor de 1530 y continuó hasta 1573 (último año analizado por Borah y Cook). ${ }^{30}$ Esta tendencia al alza se mantuvo durante el resto del siglo XVI y principios del XVII, cuando la población indígena estaba en pronunciada decadencia, pero después de 1627 el precio por fanega se estabilizó en 10 reales. En general, y siempre teniendo en cuenta que estamos trabajando con tendencias de precios con un carácter bastante hipotético, podemos concluir que el precio del maíz subió de aproximadamente 1 real y medio por fanega en 1530 hasta 4,8 reales en 1573 , y continuó subiendo hasta 1627 para estabilizarse en 10 reales, con excepción de los períodos de gran escasez. ${ }^{31}$

Ahora bien, si se hace el cálculo de la cantidad de maíz que podía comprar un obrero indígena no cualificado (invitamos al lector a hacer el cálculo para el obrero cualificado utilizando el cuadro I que da la relación salario peón-salario oficial), con el salario recibido dentro del sistema del repartimiento se obtienen los siguientes resultados para el período de 15501590: los salarios reales empezaron a subir un poco antes de 1550, así que alrededor de 1590 ya alcanzaron el triple del valor que habían tenido en 1530. La lógica conclusión, pues, es que el salario diario del peón dentro del repartimiento llegó a tener en 1590 tres veces la capacidad de compra de un salario de 1530 expresado en términos de maíz, y esto a pesar del alza en los precios de dicho grano. ${ }^{32}$

\footnotetext{
29 Borah y Cook: Price Trends..., págs. 46-47.

30 Ibídem, págs. 13-19.

31 Gibson: Los aztecas..., pág. 319.

32 Borah y Cook: Price Trends..., pág. 48.
} 


\section{CuAdro II}

RELACIÓN SALARIO-CANTIDAD DE MAÍZ

\begin{tabular}{ccc} 
Año & cantidad de maíz & evolución relativa \\
\hline 1540 & 0,052 fanega & - \\
1550 & 0,061 fanega & $+17 \%$ \\
1560 & 0,095 fanega & $+56 \%$ \\
1570 & 0,113 fanega & $+19 \%$ \\
1580 & 0,142 fanega & $+26 \%$ \\
1590 & 0,185 fanega & $+30 \%$
\end{tabular}

Fuente: Borah y Cook, Price trends, pág. 48.

No obstante, debe tenerse en cuenta que si se hubieran incluido en el cálculo de la capacidad de compra otros productos cuya tasa de aumento de precio fuera más alta que la del maíz, el valor de los salarios reales tendría que ser considerado como más bajo. Pero estos productos siempre constituyeron una parte mínima dentro del consumo total del indio. ${ }^{33}$

Sin embargo, después de 1590 nuestras fuentes sólo permiten observaciones más generales. Al no disponer de una detallada lista de precios del maíz para el período 1590-1633, necesitamos contentarnos con la peligrosa solución de analizar la tendencia general del precio del maíz y compararla con la tendencia hacia el alza de los salarios nominales. Como ya hemos señalado, la tendencia hacia el alza de los precios del maíz que se inició alrededor de 1530 continuó durante todo el resto del siglo XVI y principios del XVII, para estabilizarse en un valor aproximado de 10 reales por fanega después de 1627. Ahora bien, si aceptamos el valor de 4,8 reales por fanega hacia 1570 y lo comparamos con el valor de 10 reales del año 1632 —último año del repartimiento en términos oficiales (a excepción del sector de la minería)_, obtenemos un alza relativa de los precios reales del maíz del 108\%, mientras que en el mismo período los salarios nominales conocieron un aumento relativo del $105 \%$. Dicho de otro modo, parece que en términos relativos el alza de los salarios se mantenía a la misma altura que el alza que experimentaron los precios del maíz, lo que significaría que los salarios reales no subieron en el período de 1570 a 1632. No obstante, ya sabemos que sí hubo un alza en los salarios reales en las dos

33 Crítica también parcialmente señalada en Borah y Cook: Price trends..., pág. 48. 
últimas décadas del período 1540-1590. Entonces se puede deducir que estos resultados positivos fueron neutralizados durante el período 15901627 , cuando los precios del maíz subieron mucho más rápidamente que los salarios dentro del repartimiento.

Podemos, por tanto, concluir que la evolución del salario real dentro del repartimiento conoció dos etapas: una desde 1550 hasta finales del siglo XVI, de una verdadera alza, y la otra hacia la baja durante los tres primeras décadas del siglo XVII. Estos resultados, aunque sean muy precarios, permiten aceptar otra razón para la abolición del sistema laboral. Se puede pensar en la imposibilidad de subir los salarios, ya forzadamente bajos, a un ritmo más alto o incluso igual que los precios del maíz, quizás por razones de la estructura rígida del sistema institucionalizado o porque los amos españoles estuvieron presionando al virrey para que no aumentase los salarios oficiales en una situación de relativa crisis económica. Ello hizo, a nuestro entender, al sistema aún más inhumano de lo que ya era, presionando a los indígenas a buscar refugio en otros regímenes laborales que les ofrecieran una cierta protección contra el repartimiento. Dicho de otro modo, puesto que el medio de atracción para que el indio se incorporase al sistema, es decir, el salario, estaba aún más socavado que antes, ese sistema dejó de tener ningún interés para la población indígena, al tiempo que se despachaban órdenes reales para acabar con el carácter coactivo que el mismo tenía. Así, el sistema se destruyó a sí mismo por las contradicciones, salario y compulsión, que llevaba dentro de su organización, contradicciones que fueron alimentadas por la disminución poblacional indígena y la rigidez de la estructura de los salarios y de los precios.

\section{Relación de los salarios con el mínimo socio-vital}

Otro elemento para evaluar el alza de los salarios reales es comparar la cantidad de maíz obtenido a través del salario diario total de un peón dentro del repartimiento con la cantidad de maíz que se considera suficiente para alimentar a una persona y a las que de ella dependen. No es suficiente valorar un alza eventual en la capacidad de compra de un individuo, sin tener en cuenta las necesidades de este mismo individuo. En el México moderno, una ración diaria mínima de maíz es de medio kilo para los pobres y de kilo y medio para el promedio de los trabajadores ${ }^{34}$ Puesto que

34 Gibson: Los aztecas..., págs. 318-319. 
el trabajador dentro del repartimiento era al mismo tiempo tributario y cabeza de familia, se supone que tenía que sostener unas tres personas más con su salario. Se puede calcular la cantidad de maíz necesaria para mantener a una familia de la forma siguiente: tres porciones de medio kilo para los miembros no trabajadores y una porción de kilo y medio para el trabajador, lo que suma tres kilos de maíz al día. Esta cantidad equivale a 1/18 $(=+/-0,06)$ de fanega de maíz, estableciendo una equivalencia de 54 kilos de maíz con una fanega del mismo grano. ${ }^{35}$

$\mathrm{Si}$ aceptamos que este valor se mantuvo constante durante todo el período estudiado, podemos obtener la parte relativa del salario necesaria para comprar la cantidad de maíz que era, a su vez, indispensable para alimentar a una familia. Comparando la ración diaria, establecida en 0,06 fanega de maíz, con los valores del cuadro II se puede ver que los salarios en la década de 1540 no eran suficientes para sufragar los gastos de alimentación de la familia del peón, mientras que en la década de 1550 sí eran ya justamente suficientes. Pero sólo después de 1560 parece que pudo el indio obtener un excedente de su salario que no debía forzosamente invertir en cubrir los gastos alimenticios de su familia. Así, siempre teóricamente, el peón tuvo que invertir el $63 \%$ de su salario en comida en la década de 1560 , el $53 \%$ en la de 1570 , el $42 \%$ en la de 1580 y, finalmente, en la de 1590 el $32 \%$. Dar un valor relativo a la cantidad del salario necesaria para cubrir los gastos alimenticios de una familia entre 1590-1633 es imposible, ya que hay demasiadas variables desconocidas para ese período. Pero, puesto que hubo una caída de los salarios en esos mismos años que parece que neutralizó el progreso de las dos décadas anteriores, podemos suponer que es más que probable que el valor relativo fuese aproximadamente el de la década de 1560 , es decir, el $63 \%$.

\section{Los salarios "tasados" dentro del repartimiento frente a los "libres" del mercado laboral}

Hay un tercer método de análisis de los salarios nominales, aunque parece más limitado al no poderse establecer una relación con los salarios reales en un sentido estricto. Consiste en comparar los salarios pagados a las diferentes categorías de obreros y vigentes en este tiempo fuera del

35 Ibídem, pág. 317, nota 48 . 
repartimiento, con los salarios ofrecidos dentro de la dicha institución laboral. No obstante, hay que tener en cuenta el nivel de especialización que un obrero determinado pudiera haber logrado. Como base para este sistema de evaluación hemos utilizado una cuenta semanal en la que están registrados los gastos por mano de obra en la construcción de la catedral de la ciudad de México, relativos a la semana del 12 al 18 de diciembre de $1584 .^{36}$

\section{CUADRO III \\ OBREROS DE LA OBRA DE LA CATEDRAL DE MÉXICO}

\begin{tabular}{rcr} 
Número & Calificación laboral & Pago individual por semana \\
\hline 383 & indios, peones del tequío & 4,5 tomines \\
106 & (=repartimiento) & $4,5$ reales $)$ \\
62 & indios, peones del tequío & 4 tomines \\
1 & indios, peones del tequío & 3,5 tomines \\
57 & español, albañil & 48 tomines \\
54 & indios, albañiles jornaleros & 14 tomines \\
1 & indios, encaladores jornaleros & 14 tomines \\
4 & indios, enladrillador & 42 tomines \\
1 & indios, trompeteros del tequío & 7 tomines \\
105 & indio, oficial, cantero capitán & 31,5 tomines \\
15 & indios, canteros del tequío & 7 tomines \\
2 & indios, oficiales, canteros de los diestros & 28 tomines \\
1 & indios, oficiales canteros & 24,5 tomines \\
2 & indio, oficial cantero & 21 tomines \\
3 & indios, oficiales canteros & 17,5 tomines \\
16 & indios, oficiales canteros & 10,5 tomines \\
69 & indios, aprendices canteros & 7 tomines \\
20 & indios, hacheros del tequío & 4 tomines \\
1 & indios, hacheros (ijornaleros?) & 7 tomines \\
131 & español, carpintero & 70 tomines \\
54 & indios, carpinteros jornaleros & 14 tomines \\
64 & indios, carpinteros del tequío & 7 tomines \\
& indios, oficiales mixtos & $+/-27$ tomines
\end{tabular}

36 Cuenta publicada en Zavala, S.: Una etapa en la construcción de la catedral de México alrededor de 1585, México, [1982], págs. 30-34. 
¿Qué conclusiones podemos sacar de los datos contenidos en el cuadro? Primeramente, aunque un poco al margen del aspecto aquí analizado, que los trabajadores del repartimiento formaban el 68\% del total de los trabajadores empleados y que la mayoría de los indios repartidos (79\%) eran peones. Se puede por tanto concluir que el repartimiento era, en este contexto, el único sistema de reclutamiento de mano de obra no cualificada. $\mathrm{Al}$ mismo tiempo se observa que también los indios cualificados se vieron afectados por el sistema.

Si nos centramos en lo que estas cifras pueden aportarnos para el conocimiento de los salarios nominales de las diferentes categorías de asalariados, vemos que el indio peón reclutado con el repartimiento ganó la mitad (medio tomín al día) que el indio oficial reclutado bajo el mismo sistema (siete tomines a la semana o un tomín al día). Pero, lo que es más interesante, cuando observamos los salarios pagados fuera del repartimiento se nota inmediatamente que los mecanismos vigentes en un mercado laboral libre de toda forma de coacción, salvo la de la atracción de un salario, juegan su papel diversificador, operando además de forma inmediata un aspecto peculiar de la sociedad indiana, es decir, el multirracial. Está claro que ahora el salario se ajusta mucho más al nivel de capacitación del individuo empleado, pero también a su raza. De este modo, los indios considerados no cualificados, como son los indios hacheros, ganaban 7 tomines a la semana, mientras que los salarios de los indios cualificados variaban semanalmente de 10,5 tomines a 31,5 tomines en un caso excepcional de un puesto de mayor responsabilidad. De todas formas, parece que el salario mínimo de los no cualificados era de 14 tomines, por lo que en el caso de los salarios menores quizás tengamos que suponer que los dueños de la obra estaban reteniendo una parte del salario como si fuese una forma de peonaje por deudas. Por otra parte, se deduce que el salario de indios jornaleros mucho más especializados era de unos 28 tomines a la semana. Al mismo tiempo, se registran dos casos de salarios de españoles que parecen, aunque no muy especializados, sí cualificados, y que ganaban 48 y 70 tomines a la semana.

Ahora bien, ¿qué conclusiones podemos extraer de una comparación de los salarios pagados dentro del repartimiento y las remuneraciones pagadas fuera del mismo? Queda claro, como regla general, que un peón, igual que un oficial, podía rápidamente ganar el doble por el mismo trabajo fuera del repartimiento que dentro de esta institución laboral. No obstante, lo más grave es que parece que un indio verdaderamente especiali- 
zado podía ganar hasta cuatro veces o aún mas fuera del repartimiento, es decir, entrando en el servicio de modo voluntario. Esto explica el éxito que tenía el alquiler de sustitutos dentro de esta categoría de trabajadores. Al mismo tiempo parece que un español no verdaderamente cualificado podía ganar fácilmente seis (si aceptamos que el enladrillador fuera español) y hasta siete veces más que un indio dentro del repartimiento de la misma categoría laboral.

\section{La presión fiscal}

Como último método de valoración de los salarios nominales tenemos que analizar la presión tributaria o fiscal que recayó sobre las espaldas del indígena trabajador. Está claro que cada real que el indio tenía que entregar a la Corona era un real perdido para sí y para su comunidad, visto el hecho de que la misma Corona, apoyada y aun dirigida por los religiosos regulares, había logrado instaurar una estructura casi perfectamente dual en su colonia, a saber, la división en dos repúblicas. Así, los impuestos reales recaudados dentro de la república de los indios fluyeron sin parar y en sentido único hacia la república española.

Si analizamos el tributo en tiempos del repartimiento (1550-1632), se nota inmediatamente que los dos fenómenos, es decir, el tributo y el sistema laboral, se influyeron recíprocamente de manera decisiva. Para demostrar esta interrelación tenemos que hacer un análisis de la reforma tributaria que empezó a desarrollarse después de 1550. En general se trata de una reforma dirigida en contra de la recaudación excesiva y arbitraria que caracterizó la encomienda y a favor de una uniformidad total del tributo. ${ }^{37}$ El gobierno virreinal buscaba una diferenciación precisa y cuantitativamente fijada entre tributos destinados a la autoridad indígena, que consideramos como no reales, y tributos destinados a la autoridad española o reales. Además, y lo que es más importante, el virrey se proponía eliminar los múltiples tributos en mercancías, reduciendo todos los pagos a dinero y maíz. Al mismo tiempo, el igualamiento del tributo también fue un objetivo principal, considerando a cada jefe de familia un tributario y pagando cada cual una suma igual. También los españoles buscaban la abolición

37 Esta reforma tributaria está analizada en Miranda, J.: El tributo indígena en la Nueva España durante el siglo XVI, México, 1952, págs. 110-148. Gibson: Los aztecas..., págs. 201-206. Florescano: "La formación...", págs. 39-41. 
total de las clases tradicionalmente no sujetas al tributo, con el objetivo de eliminar cualquier posibilidad de escapar a la recaudación. Así pues, todos los elementos constituyentes de la reforma estuvieron dirigidos al establecimiento de un impuesto uniforme per capita y, por tanto, contra los impuestos pagados por las comunidades. De este modo, los nuevos reglamentos exigían (nótese bien que esto es con exclusión de los pagos hechos a la comunidad) el pago de nueve reales y medio de plata y media fanega de maíz al año. ${ }^{38}$

Existían además otros cuatro tributos adicionales que completaban el registro de exacción durante el primer siglo de la conquista, todos recaudados en reales de plata y teniendo en total un valor de seis reales por tributario. Estos eran: el Medio Real de Fábrica (de la Catedral) que se instituyó en 1552; el "real de pollo", vigente en el período de 1592-1601; el Servicio Real, un impuesto de 4 reales que fue introducido en 1592, y, finalmente, el Medio Real de Ministros establecido en 1605. ${ }^{39}$

Veamos las conclusiones que podemos sacar de esta evolución a la hora de valorar el salario nominal bajo el sistema laboral del repartimiento. Primeramente, se ve que la reforma del tributo se sitúa en la misma tendencia hacia la racionalización del sistema colonial. Con esto queremos decir que se tendió a una explotación más completa, pero al mismo tiempo mejor distribuida entre el total de los individuos indígenas tasados dentro del ámbito colonial, procurándose además la monetarización del sistema como el método idóneo para lograr aquel objetivo. Así, se puede concluir que la Corona, al exigir que los colonos pagaran a sus indios de servicio un salario en dinero y mandar, al mismo tiempo, que los indios pagaran su tributo en dinero, mostró un talante explotador y organizador bastante ingenuo. Es decir, trató de sustraer plata a sus vasallos españoles o criollos, formalmente exentos del pago de tributos, a través del sistema laboral que impuso a sus vasallos indígenas a los que, a su vez, obligó a pagarle tributo.

De todas maneras, se tiene que calcular la presión fiscal sobre los salarios tasados de los indígenas para que éstos se reduzcan a sus dimensiones correctas. El único método para lograr esto es descontar el total de impuestos anuales de los salarios que el indio ganó al año a través del trabajo prestado dentro del repartimiento. Pero en este contexto tenemos que suponer dos cosas: la primera, que ya desde 1560 el sistema del impuesto uniforme

38 Gibson: Los aztecas..., pág. 203. Miranda: El tributo..., pág. 19.

39 Gibson: Los aztecas..., págs. 207-208. Miranda: El tributo..., págs. 19-20 (no menciona el "real de pollo"). 
per capita de nueve reales y medio tuvo un arraigo más o menos total, y la segunda, que un indio tributario fue coaccionado como máximo cuatro veces al año para prestar servicios dentro del sistema del repartimiento, no realizando el resto del tiempo ninguna otra actividad a través de la cual pudiera ganar dinero. Con el método propuesto obtenemos los siguientes resultados:

\author{
CUADRO IV \\ RELACIÓN SALARIO - TRIBUTO (REALES DE PLATA)
}

\begin{tabular}{lclcc} 
& & & \multicolumn{2}{c}{ Salario-tributo } \\
Período & salario peón & tributo & en reales & excedente \\
\hline $1560-1569$ & $16 \mathrm{r}$. & $10 \mathrm{r}$. & $6 \mathrm{r}$. & $37,5 \%$ \\
$1570-1589$ & $18 \mathrm{r}$. & $10 \mathrm{r}$. & $8 \mathrm{r}$. & $44,5 \%$ \\
ca. $1590-1602$ & $24 \mathrm{r}$. & $15,5 \mathrm{r}$. & $8,5 \mathrm{r}$. & $35,5 \%$ \\
ca. $1603-1628$ & $36 \mathrm{r}$. & $15 \mathrm{r}$. & $21 \mathrm{r}$. & $58,5 \%$ \\
$1629-1632$ & $48 \mathrm{r}$. & $15 \mathrm{r}$. & $33 \mathrm{r}$. & $69 \%$ \\
& salario oficial & & & \\
\hline $1560-1589$ & $24 \mathrm{r}$. & $10 \mathrm{r}$. & $14 \mathrm{r}$. & $58,5 \%$ \\
$1590-1602$ & $48 \mathrm{r}$. & $15,5 \mathrm{r}$. & $32,5 \mathrm{r}$. & $67,5 \%$ \\
$1603-1632$ & $48 \mathrm{r}$. & $15 \mathrm{r}$. & $33 \mathrm{r}$. & $69 \%$
\end{tabular}

Se puede deducir que la presión fiscal sobre los salarios de los peones constituyó en dos tercios del tiempo en que el repartimiento estuvo vigente una carga excesiva, que absorbió al principio más del $60 \%$ de la masa total del salario. Después vino un período de alivio, probablemente porque el gobierno pretendía hacer el trabajo dentro del repartimiento más atractivo para una población indígena cada vez más reducida y más dispuesta a escapar al servicio obligatorio. De ahí que para 1603 la carga del tributo hubiese disminuido al 40\%, llegando a constituir al final del período estudiado sólo el $30 \%$. No obstante, parece que la presión fiscal era menos fuerte para el indio oficial, siempre apreciado en el medio colonial de la Nueva España por su escasez, que pagaba la misma cantidad de reales que el peón, mientras que su salario era más alto. Así, la presión fiscal que pesaba sobre su salario era relativamente menor. 
Además tenemos que mencionar las cargas eclesiásticas (sacramentos, sustento del clero...), de las propias comunidades indígenas y de sus respectivos gobiernos, junto a las que conllevaban los repartimientos de géneros. Todas juntas hicieron del salario indígena una cosa muy relativa y provocaron un drenaje financiero sistemático desde los indios y sus comunidades hacia los bolsillos privados de los españoles y, en una menor proporción, de los propios indios. Finalmente no podemos olvidar que el tributo constituyó una carga al lado del repartimiento, así que tendríamos que considerar esta institución laboral más bien como un tributo en energía añadido al tributo en dinero, en vez de apreciarlo como un complemento del tributo en dinero.

\section{Conclusiones}

A la hora de sacar conclusiones tenemos que olvidar las cifras como valores absolutos y reflexionar solamente sobre su aspecto relativo. Al mismo tiempo hay que tener en cuenta la situación histórica del medio estudiado, es decir, el Valle de México como parte del virreinato novohispano desde mediados del siglo XVI hasta aproximadamente 1633. Por tanto, debe tenerse presente que el área analizada formaba parte de un medio colonial que, como todo otro espacio en esta condición, estaba dirigido a satisfacer los deseos y necesidades de su metrópoli, suministrando a ésta las materias primas y absorbiendo las manufacturas producidas o comercializadas por la metrópoli. En este contexto del medio colonial pronto se vio, dado el carácter intensivo de la producción, la necesidad de poder contar con una reserva de mano de obra barata y abundante. Y existiendo en el Valle de México una población aborigen muy considerable, quedó desde un primer instante totalmente claro para el colono indiano que tenía que aprovechar esta circunstancia, tratando además de explotarla gratuitamente y de manera más que abusiva.

Pero rápidamente surgiría la voz de los denunciadores de esta política meramente explotadora, voz que exigió el trabajo libre y asalariado para el vasallo indígena. La Corona, siempre preocupada por el bienestar de los indios, se encontró entre dos fuegos: el de los denunciadores y el de los colonizadores que necesitaban una mano de obra barata y segura, al estar presionados, a su vez, por las demandas de la metrópoli que siempre amenazaban sus ganancias. Finalmente, la Corona, junto con su representante 
máximo en aquellas partes, el virrey don Luis de Velasco, el viejo, inventaron una fórmula que solamente iba a cumplir con una pequeña parte de la política de amparo aconsejada por los denunciadores. Además esta parte se vio neutralizada por la actitud de los españoles y aun de las propias autoridades indígenas que, aprovechando el nuevo poder adquisitivo de los indios, iniciaron a la vez un drenaje sistemático de cada posible excedente que pudiera acumularse en las comunidades indígenas. Así pues, el hecho de que los salarios crecieran aún en términos reales, por lo menos durante medio siglo, no indica nada más que una escasez de mano de obra por el acusado descenso de la población indígena. Pero también se puede pensar en una sana situación de la economía novohispana en estos tiempos, mientras que para los indios supuso una elevación de la presión sobre sus ingresos por parte de los colonos, de sus propias autoridades y también de codiciosas instituciones como la Corona, el corregimiento y la Iglesia.

Así, podemos concluir que la realidad del salario dentro del repartimiento forzoso era casi inexistente, una realidad legal anulada por la realidad "real" del medio colonial, como fue el caso de innumerables aspectos de la política de protección y buen gobierno que pretendió seguir la Corona. Por tanto, si se interpreta el repartimiento como la primera etapa en la introducción del indio en el sistema económico mercantil del español, el fracaso es evidente. $\mathrm{Y}$ es que, si el indio no tuvo ningún otro poder adquisitivo a través de sus salarios que el de adquirir productos de los repartimientos de géneros que para él no tenían casi ningún valor para enriquecer su vida material de manera real, tenemos que deducir que esta primera etapa fue negativa para el indio mismo. En consecuencia, sólo cabe considerar, en la línea de Miranda, la época del repartimiento como la segunda etapa - después de la encomienda - en la introducción del medio colonial novohispano en una economía mercantil, lejos ya de la economía de subsistencia de tiempos prehispánicos. ${ }^{40}$ No cabe duda entonces de que, a través del salario del indio, se provocó una mayor circulación de dinero hacia los mercaderes como beneficiarios particulares (en cooperación con los funcionarios reales) y hacia la Corona como beneficiario público. Falta decir que muchas veces, como lógica consecuencia de la estructura dual del medio colonial, la metrópoli iba a ser la gran beneficiada. Pero también se puede decir que el repartimiento, como fuente de mano de obra barata,

40 Miranda, J.: La función económica del encomendero en los orígenes del régimen colonial (Nueva España. 1525-1531), México, 1965, págs. 9-19. 
benefició al medio colonial novohispano, puesto que cada sociedad en vías de desarrollo económico tiene que contar con una mano de obra barata para superar los costos elevados de la fase inicial de ese desarrollo. Así, es más que probable que el sistema laboral referido fue de una importancia fundamental en el proceso de progresiva autosuficiencia económica, esta vez en el contexto de la relación de dependencia colonia-metrópoli, autosuficiencia que el medio novohispano quizás ya desde inicios del siglo XVII supo alcanzar de modo convincente. ${ }^{41}$

Como en todo otro medio colonial, esta progresiva integración en el sistema económico de la nación dominante se logró a costa de la población aborigen. Prueba de ello, y al mismo tiempo del valor nulo del salario dentro del repartimiento, es el éxito que la hacienda y las minas tuvieron como vía de escape a las exigencias laborales y del tributo. Así, el indio jamás podía alcanzar la autonomía económica, al estar siempre buscando amparo o en su comunidad endeudada o en los brazos de amos españoles que, a su vez, trataban de retener a sus indios trabajadores endeudándoles por todos los medios posibles o endeudándose por vía de atrasos en el pago del salario a sus indios peones. Fuera lo que fuera, como ya dijo el famoso Pedro de Gante, el repartimiento "no es poca ocasión para del todo ser destruidos". ${ }^{42}$

41 Bakewell, P.: Minería y sociedad en el México colonial, Zacatecas, 1546-1700, México, 1976, págs. 305-325.

42 Carta de fray Pedro de Gante al emperador, México, 15 de febrero de 1552, citada en Zavala: El servicio personal..., Vol. II, págs. 91-92. 